\title{
Geological perturbations and consequences of extreme and unexpected phenomena in the ocean
}

\author{
James P.M. Syvitski \\ University of Colorado - Boulder, Colorado USA
}

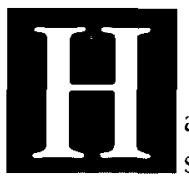

ave you ever wondered how the ocean and seafloor react to rare but high energy events, such as tsunamis, volcanic eruptions, extreme river floods, massive iceberg calving events, submarine slides and debris flows, or maybe the perfect storm that could tear apart the ocean bottom? During the 1999 TOS Science Meeting, held in Reno, Nevada (Oceanography V.12, No. 2 and supplement) a group of experts were invited to reflect on geological perturbations and consequences of such extreme events.

Jasim Imran and James Syvitski presented an overview on how rivers during extreme floods, may carry so much sediment that their fluid density may exceed the density of the ambient ocean water. When that threshold is passed, the flood waters can flow across the seafloor as a bottom boundary current. These erosive currents may be responsible for, or at least contribute to submarine canyon formation, and the turbidite fans located off of many canyons. The physical risk to offshore installations (cables, oil rigs) can be enormous when taken on a global scale.

Jodie Bourgeois reviewed the deadly hazards related to tsunamis waves and how the ocean community is responding by deploying early warning detection systems for public notice and evacuation. New underwater detection systems coupled with improved numerical models, hold out the hope for better predictions on tsunami magnitude and wave amplification in coastal waters. Thousands of lives are lost each decade, including the 1990s, even though very large events are not always involved. Even when lives are saved through evacuation, coastal destruction remains immense.

Patricia Wiberg capitalized on the popular novel The Perfect Storm (Junger, 1997) to reflect on how ocean storms create sufficient seafloor bottom stresses that when coupled with storm-generated currents can liter- ally rip apart seafloor sediment. Fines are removed and only the coarsest sediment lags behind. Very large storms may scour the seafloor at water depths in excess of $100 \mathrm{~m}$. The science challenge is to couple the dynamics of bottom boundary layer transport, based on remotely sensed observations and numerical models, to the formation and preservation of event beds. Taken together this approach may be used to interpret the geologic record from continental shelves and recover the frequency and magnitude of large ocean storms.

Veronique Robigou carried the audience into the remote and hostile world of underwater volcanoes where chemosynthetic life controls the ecosystem. Such extreme environments boggle the mind in terms of ecological adaptation (temperature, darkness, pressure, toxins). Although submarine volcanoes on spreading ridges occupy only a small portion of the global seafloor, they support a significant biomass within the ocean. Significant is the episodic behavior of seafloor vents, where vigorous bursts of hydrothermal fluids suddenly escape and give rise to spectacular microbial blooms.

Anders Elverhøi discussed the greatest threat to offshore structures (platforms, cables, pipelines), that of submarine slides and the debris flows they spawn. A remarkable feature of underwater debris flows is how fast they flow when compared to their subaerial counterparts. This comparative difference, based on laboratory experiments, is counter-intuitive because the friction of an object moving in air is so much less that the friction of a similar object moving in water. Submarine debris flows can hydroplane: essentially they ride across the seafloor on a cushion of water, at least if the flow velocity has surpassed some critical threshold. This explains the long runout distances that some submarine debris flows apparently obtain. 
John Andrews discussed one of the hot topics in paleoceanography, the extreme variability in the flux of icebergs into the North Atlantic. The discovery of Heinrich (ice-rafted debris) layers in spatially distributed sediment cores collect across the N. Atlantic have led to the postulation of massive calving events. Yet both the evidence and explanations are often contradictory. Andrews described how basal instabilities within an ice sheet, such as the Laurentide, can lead to the destabilization of other ice sheets, through feedbacks in sea level and ocean-climate interactions. Sorting out these leads and lags between icesheet behavior and calving dynamics has been difficult and yet the solution may help our understanding of deep water formation and thermohaline circulation.

Four of these six papers are presented here for the members and readers of Oceanography, as a special collection to help us understand some of the hottest topics in geo-oceanography.

\section{REFERENCES}

Junger, S., 1997: The Perfect Storm. W.W. Norton \& Co., $227 \mathrm{pp}$.

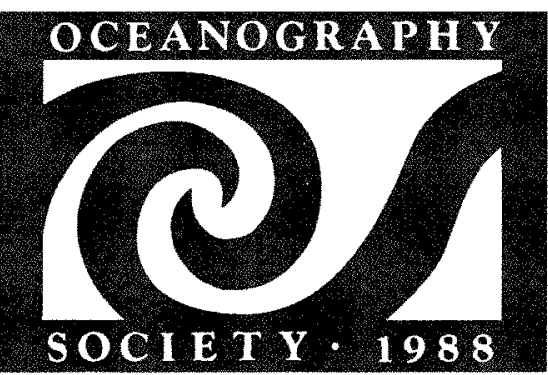

